\title{
Pre-Clinical Cushing's Syndrome with Body Weight Loss and Normal Circadian Rhythm of Blood Pressure
}

\author{
Taku Iwami, Tetsuya Nakamura, Nogiku Niwamae, Takahiro Yamagishi, Toshihiro Utsugi and Ryozo Nagai
}

\begin{abstract}
A 68-year-old woman was referred for evaluation of an incidentally discovered left adrenal mass. Her chief complaint was body weight loss. She showed no symptoms or signs suggestive of Cushing's syndrome. The circadian rhythm of blood pressure was also normal. Hormonal assessment revealed an abnormal diurnal variation in serum cortisol levels, suppressed baseline plasma adrenocorticotrophic hormone, and nonsuppression of serum and urinary cortisol with the dexamethasone suppression test. Adrenal scintigraphy with ${ }^{131}$ I-6-beta-iodomethyl-norcholesterol showed uptake on the left adrenal and inhibition of the contralateral adrenal gland. She was diagnosed as pre-clinical Cushing's syndrome. Due to the lack of clinical symptoms and the risks of surgery, we emphasize the importance of careful assessment of the cortisol metabolism and scintigraphic scanning under dexamethasone suppression to avoid post-surgical Addisonian crisis. (Internal Medicine 37: 528-533, 1998)
\end{abstract}

Key words: adrenal incidentaloma, dexamethasone, cortisol

\section{Introduction}

Incidental adrenal tumors or "incidentaloma" are a frequently diagnosed condition both in autopsy series (1) and computed tomography (CT) carried out for unrelated reasons (2). Since the advent of sensitive noninvasive methods to image the abdomen, such as CT scanning, the discovery of incidental adrenal masses has become fairly common. Most studies report an incidence of silent adrenal tumors of $1 \%$ to $2 \%$ of patients examined by CT scanning $(1,2)$. In some of these patients, subtle or frank overproduction of glucocorticoids without physical signs or symptoms of Cushing's syndrome has recently been described (3-17). This condition is known as "pre-clinical Cushing's syndrome", and the prevalence of pre-clinical Cushing's syndrome among adrenal "incidentalomas" has been found to vary between 5\% and 14\% (4-6). It is important to clarify whether the adrenal tumors incidentally discovered are functionally active, even when symptoms and physical signs are absent, because unilateral adrenalectomy in such a patient poses a potential risk of Addisonian crisis (4, 5, 7-9). We herein report a patient with pre-clinical Cushing's syndrome who was completely asymptomatic except for a subtle glucose intolerance. Her chief complaint was body weight loss. Subsequently, she underwent adrenalectomy and required a substitutive treatment with hydrocortisone after surgery.

\section{Case Report}

A 68-year-old woman was referred to us for the evaluation of an adrenal incidentaloma. She originally presented to her home doctor with the complaint of body weight loss. She had no other clinical symptoms and was suspected to have a malignant tumor. In an attempt to confirm this suspicion, she underwent chest and abdominal CT, and other examinations to determine the cause of body weight loss. Her abdominal CT showed a 2 $\mathrm{cm}$ round, well-circumscribed mass in her left adrenal gland (Fig. 1).

For editorial comment, see p 497.

Following transfer to our hospital, we examined the possibility of adrenal cancer. The patient complained of body weight loss, yet the results of a physical examination were unremarkable; blood pressure was $120 / 65 \mathrm{mmHg}$, heart rate $76 \mathrm{bpm}$, height $1.55 \mathrm{~m}$, and weight $44 \mathrm{~kg}$. Her body weight was $48 \mathrm{~kg} 7$ months before admission. The circadian rhythm of blood pressure (ABPM-630, Colin, Tokyo) was also normal (Fig. 2). Signs of Cushing's syndrome, virilization and other abnormalities were not present on physical examination. Routine blood tests (serum sodium, potassium, carbon dioxide, creatinine, and fasting serum glucose) were within the normal ranges. In an oral

From the Second Department of Internal Medicine, Gunma University School of Medicine, Maebashi

Received for publication October 17, 1997; Accepted for publication March 10, 1998

Reprint requests should be addressed to Dr. Tetsuya Nakamura, the Second Department of Internal Medicine, Gunma University School of Medicine, 3-39-15 Showa-machi, Maebashi 371-8511 

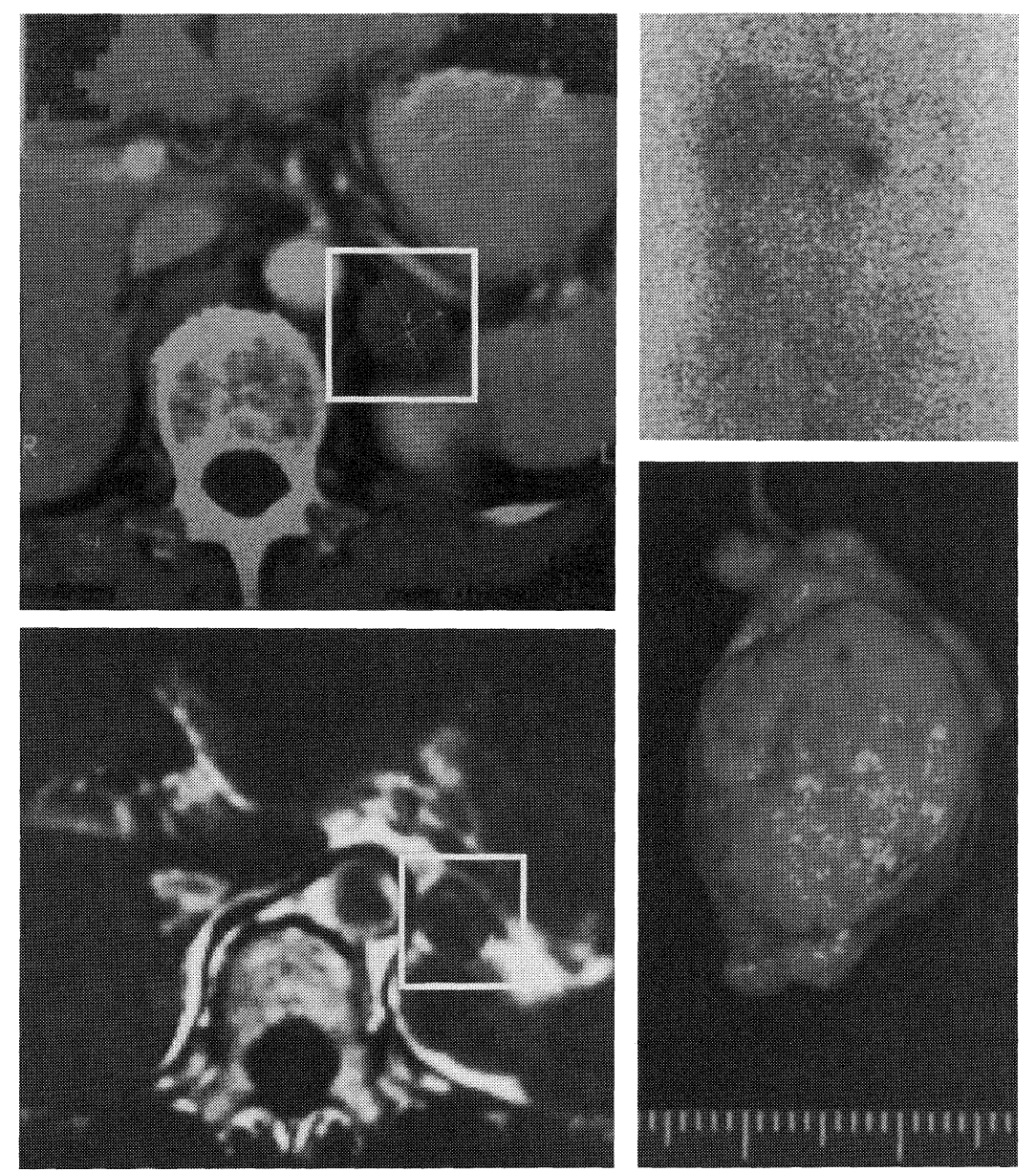

Figure 1. Computed tomography (left upper panel) and magnetic resonance imaging (left lower panel) of adrenal tumor, preoperative anterior adrenal scintigraphy with ${ }^{131}$ I-6-beta-iodomethyl-norcholesterol with dexamethazone suppression (right upper panel), and gross appearance of resected adrenal tumor (right lower panel). Abdominal computed tomography and magnetic resonance imaging show a $2 \mathrm{~cm}$ round, well-circumscribed mass in the left adrenal gland. Anterior adrenal scintigraphy with ${ }^{131}$ I-6-beta-iodomethyl-norcholesterol shows uptake on the left adrenal and inhibition of the contralateral adrenal gland. The excised adrenal tumor exhibits a well capsulated and poorly vascularized yellow nodular mass, weighing $5.7 \mathrm{~g}$ and of size $2.2 \times 1.8 \times 1.7 \mathrm{~cm}$.

glucose tolerance test before surgery, plasma glucose was 5.6 $\mathrm{mmol} / l, 9.3 \mathrm{mmol} / l, 11.1 \mathrm{mmol} / l, 8.8 \mathrm{mmol} / l$ and $6.8 \mathrm{mmol} / l$ before and 30 minutes, 60 minutes, 90 minutes and 120 minutes after a $75 \mathrm{~g}$ oral glucose administration, respectively, indicating a slight glucose intolerance.

Table 1 summarizes the circadian changes in serum cortisol, plasma adrenocorticotrophic hormone $(\mathrm{ACTH})$, plasma renin activity and plasma aldosterone concentration. Before surgical removal of the adrenal tumor, the patient's serum cortisol levels were slightly elevated, accompanied by a loss of diurnal rhythm. Plasma ACTH was either low or undetectable throughout the day. Table 2 summarizes the hormonal data before and after dexamethasone administration, which disclosed slightly elevated basal urinary free cortisol and 17-hydroxycorticoid and no suppression of serum and urinary free cortisol after dexamethasone (Table 2). Serum cortisol after 2 or $8 \mathrm{mg}$ dexamethasone exceeded half of the value before dexamethasone, indicating a lack of suppression of cortisol by dexamethasone.

Adrenal scintigraphy with ${ }^{131}$ I-6-beta-iodomethylnorcholesterol showed uptake on the left adrenal and inhibition of the contralateral adrenal gland (Fig. 1). Bilateral adrenal venous catheterization was performed, demonstrating that the cortisol concentration in the adrenal venous blood from the side of the mass lesion $(79.4 \mu \mathrm{g} / \mathrm{dl})$ was greater than in the contralateral side $(15.6 \mu \mathrm{g} / \mathrm{dl})$. The plasma aldosterone concentrations in the adrenal venous blood from the side of the mass lesion $(150 \mathrm{pg} / \mathrm{ml})$ was also higher than in the contralateral side $(26 \mathrm{pg} / \mathrm{ml})$. The plasma renin activities in the adrenal venous 


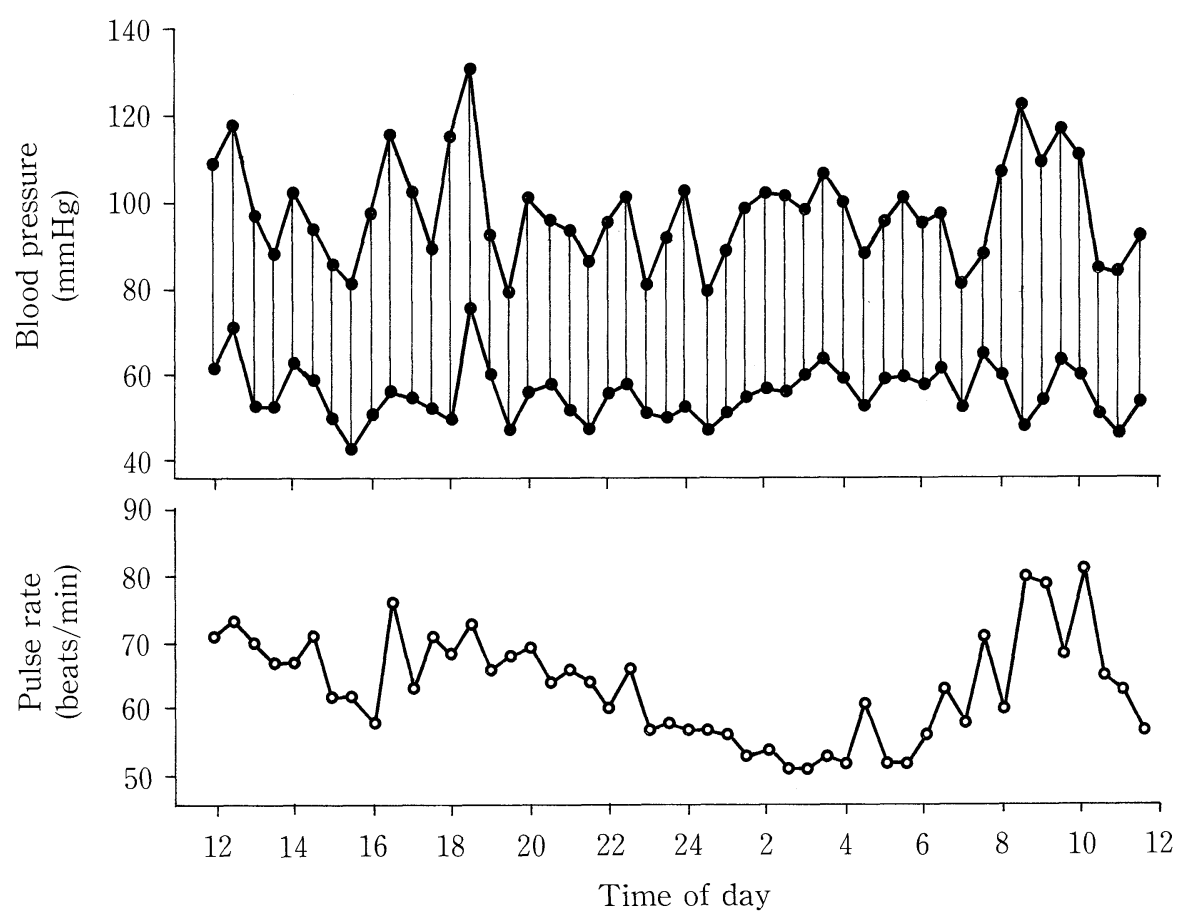

Figure 2. Circadian rhythm of systolic and diastolic blood pressure and heart rate. Systolic and diastolic blood pressures show a nocturnal fall.

Table 1. Circadian Change in Serum Cortisol, Plasma Adrenocorticotrophic Hormone (ACTH), Plasma Renin Activity (Renin) and Plasma Aldosterone Concentration (Aldosterone) before and after Surgery

\begin{tabular}{lrccccc}
\hline & & \multicolumn{5}{c}{ Time of Day } \\
& & $8: 00$ & $12: 00$ & $16: 00$ & $20: 00$ & $24: 00$ \\
\cline { 3 - 7 } & & & & & & \\
Before surgery & & & & & \\
ACTH & $(\mathrm{pg} / \mathrm{ml})$ & $<5$ & 8 & $<5$ & $<5$ & $<5$ \\
Cortisol & $(\mu \mathrm{g} / \mathrm{dl})$ & 19.7 & 15.4 & 17.2 & 11.0 & 11.9 \\
Renin & $(\mathrm{ng} / \mathrm{ml} / \mathrm{h})$ & 0.9 & 1.5 & 0.4 & 0.5 & 0.2 \\
Aldosterone & $(\mathrm{pg} / \mathrm{ml})$ & 28 & 46 & 24 & 23 & $<10$ \\
After surgery & & & & & & \\
ACTH & $(\mathrm{pg} / \mathrm{ml})$ & 22 & 8 & $<5$ & 6 & 6 \\
Cortisol & $(\mu \mathrm{g} / \mathrm{dl})$ & 1.4 & 17.6 & 19.8 & 6.7 & 1.8 \\
Renin & $(\mathrm{ng} / \mathrm{ml} / \mathrm{h})$ & 0.2 & 0.1 & $<0.1$ & 0.2 & $<0.1$ \\
Aldosterone & $(\mathrm{pg} / \mathrm{ml})$ & $<10$ & $<10$ & $<10$ & $<10$ & $<10$ \\
\hline
\end{tabular}

Normal ranges of plasma ACTH, serum cortisol, plasma renin activity, and plasma aldosterone concentration were $9 \mathrm{pg} / \mathrm{ml}$ to $52 \mathrm{pg} / \mathrm{ml}$, less than $25 \mu \mathrm{g} / \mathrm{dl}, 0.3 \mathrm{ng} / \mathrm{ml} /$ h to $2.9 \mathrm{ng} / \mathrm{ml} / \mathrm{h}$ and $30 \mathrm{pg} / \mathrm{ml}$ to $150 \mathrm{pg} / \mathrm{ml}$, respectively.

blood from the side of the mass lesion and from the contralateral side were $0.5 \mathrm{ng} / \mathrm{ml} / \mathrm{h}$ and $0.5 \mathrm{ng} / \mathrm{ml} / \mathrm{h}$, respectively. A 24-hour urine collection revealed vanillylmandelic acid of $4.99 \mathrm{mg} /$ day (normal 1.50 to $4.90 \mathrm{mg} /$ day), metanephrines of $0.09 \mathrm{mg} /$ day (normal 0.04 to $0.18 \mathrm{mg} / \mathrm{day}$ ), epinephrine of $12.3 \mu \mathrm{g} / \mathrm{day}$ (normal 3 to $41 \mu \mathrm{g} / \mathrm{day}$ ), and norepinephrine of $121.1 \mu \mathrm{g} / \mathrm{day}$ (normal 31 to $160 \mu \mathrm{g} /$ day), indicating a normal adrenomedullary function.

During surgery, an adrenal adenoma, weighing $5.7 \mathrm{~g}$ with $2.2 \times 1.8 \times 1.7 \mathrm{~cm}$ in diameter, was removed (Fig. 1). The normal adrenal gland adjacent to the adenoma was compressed but not atrophic histologically. Post-surgical substitutive treatment with oral hydrocortisone was started and a second hormonal assessment was carried out after 2 weeks. Table 1 shows the circadian 
patterns of serum cortisol and plasma ACTH. Oral hydrocortisone $10 \mathrm{mg}$ was administered three times a day at 8:30 AM, 12:30 PM and 18:30 PM. After surgery, plasma ACTH became higher than before surgery, but serum cortisol, plasma renin activity and plasma aldosterone were still low at 8:00 AM, the time before taking hydrocortisone.

On the day of examining the responses of serum cortisol to ACTH or corticotropin-releasing hormone, the substitutive hydrocortisone was discontinued in the morning. The response of serum cortisol to the intravenous injection of either ACTH or corticotropin-releasing hormone was also suppressed (Table
3). After surgery, plasma glucose was $4.9 \mathrm{mmol} / l, 7.1 \mathrm{mmol} / l$, $6.7 \mathrm{mmol} / l, 7.5 \mathrm{mmol} / l$ and $8.2 \mathrm{mmol} / l$ before and 30 minutes, 60 minutes, 90 minutes and 120 minutes after $75 \mathrm{~g}$ oral glucose administration, respectively.

The substitutive treatment with hydrocortisone was discontinued 5 months after the surgery. Her body weight was slightly decreased from $44 \mathrm{~kg}$ before the surgery to $41 \mathrm{~kg}$ at this time. One month after the discontinuation of hydrocortisone, plasma $\operatorname{ACTH}(76 \mathrm{pg} / \mathrm{ml})$, serum cortisol $(8.2 \mu \mathrm{g} / \mathrm{dl})$ and plasma renin activity $(0.8 \mathrm{ng} / \mathrm{ml} / \mathrm{h})$ were all normal; however, plasma aldosterone $(10 \mathrm{pg} / \mathrm{ml})$ was still low.

Table 2. Urinary Free Cortisol, Urinary 17-hydroxycorticoid (17 OHCS), Plasma Adrenocorticotrophic Hormone (ACTH), Serum Cortisol and Fasting Plasma Glucose before and during Oral Administration of Dexametha sone at a Dose of $2 \mathrm{mg} / \mathrm{day}$ or $8 \mathrm{mg} /$ day

\begin{tabular}{|c|c|c|c|c|c|}
\hline \multirow[b]{2}{*}{ Urinary free cortisol (mg/day) } & \multicolumn{3}{|c|}{ before dexamethasone } & \multirow{2}{*}{$\frac{\text { after } 2 \mathrm{mg}}{73.7}$} & \multirow{2}{*}{$\frac{\text { after } 8 \mathrm{mg}}{44.0}$} \\
\hline & 259 & 282 & 89.4 & & \\
\hline Urinary 17-OHCS (mg/day) & 10.8 & 12.7 & 8.3 & 6.9 & 4.9 \\
\hline Plasma ACTH (pg/ml) & - & - & 7 & 9 & $<5$ \\
\hline Serum cortisol $(\mu \mathrm{g} / \mathrm{dl})$ & - & - & 14.6 & 17.4 & 7.8 \\
\hline Fasting plasma glucose (mg/dl) & - & - & 82 & 149 & 189 \\
\hline
\end{tabular}

Dexamethasone was administered orally every 6 hours at doses of $0.5 \mathrm{mg}$ and $2 \mathrm{mg}$ for 2 consecutive days in the $2 \mathrm{mg}$ - and $8 \mathrm{mg}$-suppression tests, respectively. Plasma ACTH and serum cortisol were measured at $8 \mathrm{AM}$ before breakfast. Normal ranges of urinary free cortisol and 17-OHCS are 30 to $100 \mathrm{mg}$ /day and 2.2 to $7.3 \mathrm{mg} /$ day, respectively.

Table 3. Plasma Adrenocorticotrophic Hormone (ACTH) and Serum Cortisol in Response to Intravenous Injection of ACTH and Human Corticotropin-Releasing Hormone (hCRH)

Response of plasma ACTH and serum cortisol to intravenous injection of ACTH

\begin{tabular}{lccc}
\hline & Basal & $30 \mathrm{~min}$ & $60 \mathrm{~min}$ \\
\cline { 2 - 4 } & & & \\
before surgery & $<5$ & $<5$ & 31.6 \\
ACTH $(\mathrm{pg} / \mathrm{ml})$ & 10.3 & 24.7 & 16 \\
Serum cortisol $(\mu \mathrm{gg} / \mathrm{dl})$ & & & 3.7 \\
after surgery & 25 & 3.6 & 3.7 \\
ACTH $(\mathrm{pg} / \mathrm{ml})$ & 2.7 & 12 & \\
Serum cortisol $(\mu \mathrm{g} / \mathrm{dl})$ & & & \\
\hline
\end{tabular}

Response of plasma ACTH and serum cortisol to intravenous injection of hCRH

\begin{tabular}{lcccccc}
\hline & Basal & 15 min & 30 min & 60 min & 90 min & 120 min \\
\cline { 2 - 6 } & & & & & & \\
before surgery & $<5$ & 9 & 11 & 7 & $<5$ & $<5$ \\
$\quad$ ACTH $(\mathrm{pg} / \mathrm{ml})$ & 12.1 & 16.9 & 19.6 & 22.7 & 15.5 & 13.1 \\
$\quad$ Serum cortisol $(\mu \mathrm{g} / \mathrm{dl})$ & 23 & 72 & 110 & 100 & 83 & 59 \\
after surgery & 1.1 & 1.4 & 2.0 & 1.9 & 1.7 & 1.8 \\
$\quad$ ACTH $(\mathrm{pg} / \mathrm{ml})$ & & & & &
\end{tabular}

ACTH and hCRH were injected intravenously at doses of $0.25 \mathrm{mg}$ and $100 \mu \mathrm{g}$, respectively. 


\section{Discussion}

Charbonnel et al (3) reported in 1981 the first well-documented case of pre-clinical Cushing's syndrome and coined this term to define it. Finally, McLeod et al (4) found that 5\% of their adrenal adenomas fulfilled the following criteria: 1) an incidentally discovered adrenal tumor that proved to be a benign cortical adenoma, 2) no clinical signs or complaints directly attributable to Cushing's syndrome or adrenal disease, 3) loss of diurnal rhythm of cortisol or nonsuppression of serum and urinary cortisol following 2 and $8 \mathrm{mg}$ of dexamethasone with suppressed or normal baseline plasma $\mathrm{ACTH}$, and 4) unilateral or predominantly positive unilateral uptake of radioactive cholesterol with scintigraphic scanning. Although there is still controversy regarding the real existence of pre-clinical Cushing's syndrome, the present patient exhibited the hormonal features of adrenal Cushing's syndrome but with no physical sign or symptom of Cushing's syndrome except for a slight glucose intolerance. The clinical and laboratory features of the present case fulfill the diagnostic criteria of pre-clinical Cushing's syndrome reported recently (17).

The anthropometric measures of this patient showed no significant difference from a typical Japanese woman. However, her chief complaint was body weight loss. We could not find any report of patients with ovart Cushing's syndrome complicated with body weight loss. In reported cases of preclinical Cushing's syndrome, the body weight is usually normal to slightly elevated (3-17). Thus, it is very rare to see a patient with a cortisol-producing adrenal adenoma who complains of body weight loss. Recent evidence suggests that the glucocorticoid effects to control nutrient intake and metabolism are mediated through two steroid receptor subtypes, the type I and type II receptors (18), located within the hypothalamic paraventricular nucleus. The type I receptor is tonically activated and maintains the ingestion and deposition of fat. The type II receptor is phasically activated by the moderately elevated levels of glucocorticoid normally reached during the circadian peak. The activation of type II receptors is required for the surge in carbohydrate ingestion and metabolism. In contrast, an exogenous administration of glucocorticoid induces muscle wasting (19). An inhibition of skeletal muscle protein synthesis and body weight reduction have been constantly observed in glucocorticoid-treated animals (19). Although the definite cause of body weight loss is not clear in the present case, the minimally elevated cortisol may induce muscle wasting, but may not be high enough to stimulate type II receptors in the hypothalamus, which could result in body weight loss. It may take time to recover from muscle wasting after the surgical removal of an adrenal adenoma.

She also showed normal blood pressure with a normal circadian rhythm of blood pressure. This normal circadian variation of blood pressure is interesting, because a loss of nocturnal fall or even a nocturnal rise in blood pressure has been reported in overt Cushing's syndrome (20). This is the first report of measuring the circadian rhythm of blood pressure in pre-clinical Cushing's syndrome, using an ambulatory blood pressure monitoring system.

Adrenal scintigraphy with radioactive cholesterol has been well demonstrated to provide a reliable measure of adrenocortical function in addition to being a localizing technique $(3,10$ 12). Virkkala et al (10) performed thorough hormonal assessment plus scintigraphic scanning with radioactive cholesterol under dexamethasone suppression in 19 patients with incidentally-discovered adrenal tumors. They emphasized the importance of careful assessment of the cortisol metabolism and scintigraphic scanning under dexamethasone suppression in the examination of these patients. It is very important to know the degree of suppression upon the contralateral adrenal gland through analysis of a scintigraph scan, to estimate the potential risk of Addisonian crisis after adrenalectomy. In the present patient, adrenal scintigraphy with ${ }^{131} \mathrm{I}$-6-beta-iodomethylnorcholesterol showed uptake on the left adrenal and inhibition of the contralateral adrenal gland.

There have been several reports describing the risks of adrenocortical insufficiency after adrenalectomy in patients with pre-clinical Cushing's syndrome (4, 5, 7-9). In the present patient, the level of serum cortisol at 8:00 AM and the responses of serum cortisol to corticotropin-releasing hormone (CRH) and ACTH were suppressed after adrenalectomy. Although the tumor appeared to be clinically nonfunctional, these data indicate that the tumor was autonomously producing cortisol, and suppressing the contralateral adrenal gland. At the former hospital, the patient was suspected to have a malignant neoplasm, and there was the possibility that the adrenal tumor, incidentally found, might be a adrenal cancer. If unilateral adrenalectomy in this patient had been performed without sufficient hormonal study and substitutive treatment, the risk of Addisonian crisis would have been significant.

Uniform guidelines have not yet been established for the management of pre-clinical Cushing's syndrome. Surgical treatment is generally recommended, to prevent the development of long-term complications of subtle corticoid excess (6). To our knowledge, the transition from pre-clinical Cushing's syndrome to overt Cushing's syndrome has been reported in only two cases $(7,13)$. The possibility of advancement from preclinical Cushing's syndrome to overt Cushing's syndrome seems to be low, especially in older patients. Considering the lack of clinical symptoms and the risks of surgical treatment, including postoperative adrenal insufficiency, it is imperative to carefully evaluate the necessity of surgical treatment especially in older patients.

In summary, we treated a case of pre-clinical Cushing's syndrome complaining of body weight loss. The circadian rhythm of blood pressure was normal. When adrenalectomy is performed in pre-clinical Cushing's syndrome or adrenal incidentaloma, we emphasize the importance of a careful assessment of the cortisol metabolism and a scintigraphic scan under dexamethasone suppression to avoid post-surgical Addisonian crisis. It is necessary to carefully evaluate the necessity of surgical treatment especially in older patients. 


\section{Cushing's Syndrome with Body Weight Loss}

\section{References}

1) Abecassis M, McLoughlin MJ, Langer B, Kudlow JE. Serendipitous adrenal masses: Prevalence, significance, and management. Am J Surg 149: $783,1985$.

2) Mitnick JS, Bosniak MA, Megibow AJ, Naidich DP. Non-functioning adrenal adenomas discovered incidentally on computed tomography. Radiology 148: 495, 1983.

3) Charbonnel B, Chatal JF, Ozanne P. Does the corticoadrenal adenoma with 'Pre-Cushing's Syndrome' exist? J Nucl Med 22: 1059, 1981.

4) McLeod MK, Thompson NW, Gross MD, Bondeson AG, Bondeson L. Sub-clinical Cushing's syndrome in patients with adrenal gland incidentalomas. Pitfalls in diagnosis and management. Am Surg 56: 398, 1990.

5) Reincke M, Nieke J, Krestin GP, Saeger W, Allolio B, Winkelmann W. Pre-clinical Cushing's syndrome in adrenal 'incidentalomas': Comparison with adrenal Cushing's syndrome. J Clin Endocrinol Metab 75: 826, 1992.

6) Fernandez-Real J-M, Ricart-Engel W, Simo R. Pre-Clinical Cushing's Syndrome: Report of Three Cases and Literature Review. Horm Res 41: 230, 1994.

7) Huiras CM, Pehling GB, Caplan RH. Adrenal insufficiency after operative removal of apparently nonfunctioning adrenal adenomas. JAMA 261: 894, 1989.

8) Copeland PM. The incidentally discovered adrenal mass. Ann Intern Med 98: $940,1983$.

9) Beyer HS, Doe RP. Cortisol secretion by an incidentally discovered nonfunctional adrenal adenoma. J Clin Endocrinol Metab 62: 1317, 1986.

10) Virkkala A, Valimaki M, Pelkonen R, et al. Endocrine abnormalities in patients with adrenal tumors incidentally discovered on computed tomog- raphy. Acta Endocrinol (Copenh) 121: 67, 1989.

11) Beierwaltes $\mathrm{WH}$, Sturman MF, Ryo U, Ice RD. Imaging functional nodules of the adrenal glands with ${ }^{131}$ I-19-Iodocholesterol. J Nucl Med 15: 246, 1974.

12) Rizza RA, Wahner HW, Spelsberg TC, Northcutt RC, Moses HL. Visualization of nonfunctioning adrenal adenomas with iodocholesterol: Possible relationship to subcellular distribution of tracer. J Nucl Med 19: 458, 1978.

13) Hensen J, Buhl M, Bahr V, Oelkers W. Endocrine activity of the "silent" adrenocortical adenoma is uncovered by response to corticotropin-releasing hormone. Klin Wochenschr 68: 608, 1990.

14) Bertagna $C$, Orth DN. Clinical and laboratory findings and results of therapy in 58 patients with adrenocortical tumors admitted to a single medical center (1951 to 1978). Am J Med 71: 855, 1981.

15) Cugini P, Campisi C, Castagna G, et al. Pre-Cushing's Syndrome: a case report. Endocrinol Jpn 39: 407, 1992.

16) Tsuboi Y, Ishikawa S, Fujisawa G, Okada K, Saito T. Possible PreCushing's syndome due to an adrenal adenoma incidentally discovered. Endocr J 42: 509, 1995.

17) Suda T. Preclinical Cushing's syndrome and adrenocorticotropic hormone-independent bilateral adrenocortical macronodular hyperplasia. Intern Med 36: 601, 1997 (Editorial; comment).

18) Tempel DL, Leibowitz SF. Adrenal steroid receptors: interactions with brain neuropeptide systems in relation to nutrient intake and metabolism. J Neuroendocrinol 6: 479, 1994.

19) Dardevet D, Sornet C, Taillandier D, Savary I, Attaix D, Grizard J. Sensitivity and protein turnover response to glucocorticoids are different in skeletal muscle from adult and old rats. Lack of regulation of the ubiquitin-proteasome proteolytic pathway in aging. J Clin Invest 96: 2113, 1995.

20) Imai $Y$, Abe K, Sasaki S, et al. Altered circadian blood pressure rhythm in patients with Cushing's syndrome. Hypertension 12: 11, 1988. 